\title{
La historia fragmentada de los monumentos públicos: el proceso de identificación y su significado en la actualidad
}


THE FRAGMENTED HISTORY OF PUBLIC MONUMENTS: THE IDENTIFICATION PROCESS AND ITS MEANING TODAY

ABSTRACT

The public monuments protected the construction of the Liberal State in its mission to model the new cities as symbols of cultural progress. Through selective memory, a unique and universal history imposed on the community was reconstructed through the exaltation of great men and historical milestones in order to configure a shared national identity. Marginal groups, including women, remained excluded from this identity project. The present work shows the results of a comparative study between two European cities, Madrid-Stockholm, with the aim of verifying that identity discourse is constituted by public sculptures. For this purpose, gender was used as a category of analysis allowing to explain how societies determine social roles of action in a different way. The results obtained after the analysis raised questions about the link between the context of current public space and the function of commemorative sculptures.

\section{Keywords}

Memorials, public sculpture, women, national identity, gender studies.

\section{RESUMEN}

Los monumentos públicos ampararon la construcción del Estado Liberal en su cometido de modelar las nuevas ciudades como símbolos del progreso cultural. Mediante una memoria selectiva se reconstruyó una historia única y universal impuesta a la colectividad a través de la exaltación de prohombres e hitos históricos con el fin de configurar una identidad nacional compartida. Los grupos marginales, entre ellos las mujeres, permanecieron excluidos de este proyecto identitario. En el presente trabajo se muestran los resultados de un estudio comparativo entre dos ciudades europeas, MadridEstocolmo, con el objetivo de verificar que discurso identitario se constituye mediante las esculturas públicas. Para tal fin, se hizo uso de una metodología feminista en la cual el género fue empleado como categoría de análisis permitiendo explicar cómo las sociedades determinan los roles sociales de acción de forma diferenciada. Los resultados obtenidos tras el análisis plantearon una reflexión efectuada desde un marco interseccional, acerca del vínculo entre el contexto del espacio público actual y la significación de las esculturas conmemorativas en el proceso de identificación.

\section{Palabras clave}

Monumentos conmemorativos, escultura pública, mujeres, identidad nacional, estudios de género. 


\section{INTRODUCCIÓN}

La Antigüedad clásica alberga los principios constitutivos de los monumentos conmemorativos como artefactos en los cuales prima una finalidad utilitaria. El pragmatismo escultórico y arquitectónico producido durante el Imperio Romano $(\mathrm{IdC}-\mathrm{V} \mathrm{dC}$ ) reside en su propósito didáctico y propagandístico; la noción de arte formulada al servicio del poder. Los sistemas políticos y religiosos, a lo largo de la Historia, se han apropiado del arte, como símbolo representacional de una cultura particular, ante la pretensión de aleccionar al conjunto social que habita dentro de unas estructuras determinadas. La lógica inherente al monumento conmemorativo, como elementos escultóricos representativos de personajes, hazañas históricas o aspectos relacionados con la comunidad que pretenden no ser olvidados, sugiere su destrucción o por el contrario, su proliferación atendiendo a la caída o ascenso de un régimen, manifestando, así mismo, su carácter simbólico.

\section{El arte es comunicación [...] La comunicación requiere algún tipo de código de símbolos, es decir cambios en varios niveles, para hacer llegar con mayor o menor éxito a otras vivencias que bullen en las profundidades de la conciencia o que subyacen en la colectividad, pero que no todos están en condiciones de expresarlas aunque sí de contemplarlas. Siendo el arte comunicación y mensaje, provoca reacciones, formas de comportamiento y actitudes entre los que reciben el mensaje (Malo, 2006, p.173).}

Desde una perspectiva histórico-artística desde el siglo XIX las estatuas conmemorativas fueron adquiriendo un carácter cívico, llegando, a principios del siglo XX a convertirse en un elemento esencial de las ciudades. Durante este período se manifestó un fenómeno de monumentalización que configuró el espacio público dotándolo de esculturas de carácter figurativo que conmemoraban prohombres como símbolo del Estado Moderno. Este acontecimiento se extendió por toda Europa y parte de América pero tuvo especial incidencia en España, como muestra el gran número de esculturas conmemorativas dispuestas en las calles de Madrid. El fin de monumentalizar las ciudades en general y las capitales en particular, mediante esculturas conmemorativas como rasgo particular del progreso cultural, se fundamentó en el pasado.

El proceso no se debió sólo a que hubiera hechos o figuras que merecieron el recuerdo, desde una determinada escala de valores históricos, o al simple embellecimiento urbano, sino a una insaciable sed de recuerdos. Parece como si la memoria hubiese irrumpido como una imperiosa fuerza hasta quedar plasmada en los más diversos hechos o figuras. La más profunda acepción de monumentalizar es, pues, la de traer recuerdos. De alguna manera, pues, puede decirse que el fervor hacia una tipología, con todas sus implicaciones, precedió a la elección concreta de su contenido (Reyero, 2003, p.41).

El éxito del monumento conmemorativo estuvo determinado por las remodelaciones planificadas, mediante ensanches y bulevares, de la ciudad decimonónica y su concepción como espacio público, donde conjugar arte y vida. Esta época constituye una fase de desarrollo del capitalismo individual y de consolidación de la burguesía, donde la ciudad es conformada como un producto capitalista, desistiendo de su carácter como lugar de aglomeración (Solá, 1973). El espacio público se configura, no únicamente con una finalidad práctica sino también, aunque en menor grado, estética. 
El bulevar y el parque son además expresión de una nueva estética urbana hecha de perspectivas, donde la arborización y los edificios públicos juegan un papel preponderante, y además cuidada hasta el detalle, pues todo se realiza a partir de los mismos elementos constructivos e industrializados, entre los cuales el sistema del amueblamiento urbano se destaca por su belleza y funcionalidad (Gamboa, 2003, p.15).

Las reformas urbanas constituyeron la expresión de la modernización, asentadas sobre un interés estético acorde con la percepción de las nuevas formas sociales. Los monumentos conmemorativos fueron consolidados como elementos ornamentales en la expansión del espacio urbano, así como artefactos imprescindibles para la cimentación de los nuevos valores; una doble función que intensificó su disposición por toda Europa.

Desde aquel presente se rescataron valores morales del pasado, encarnados en personajes ilustres y hechos históricos trascendentales, ante la demanda de nuevos ídolos, aleccionadores de la moral burguesa-liberal. Pretexto para la construcción de una identidad nacional compartida, con una función didáctica que educara a los y las ciudadanas coetáneas pero, también, a futuras generaciones.

Las estatuas deberían leerse también como un símbolo de identidad política o como un reflejo de la ideología del régimen en turno, y no únicamente como un discurso estético. Las iniciativas podían provenir de particulares o del Estado, pero todas, en el fondo, buscaban contribuir a la conformación de la identidad nacional (Zárate, 2003, p.439).

La proliferación de las esculturas conmemorativas no estuvo determinada en última instancia por factores estéticos ni para rememorar cuestiones históricas sustanciales sino, más bien, para ejercer una función instructiva, condicionada por las élites políticas. Las esculturas figurativas, como emblemas del Estado, se alzaron en representación de los valores nacionales a modo de personajes a quienes se les concede el honor y la credibilidad. Esta idea se reforzó en la disposición de las esculturas sobre pedestales aludiendo al carácter heroico y divino del personaje y produciendo y reforzando un efecto distanciador y de inaccesibilidad. "Las esculturas son normalmente figurativas y verticales y sus pedestales forman una parte importante de la escultura, puesto que son mediadores entre el emplazamiento verdadero y el signo representacional» (Krauss, 1979, p.63).

Los monumentos conmemorativos responden a una intersección espacio-temporal entre la ubicación y el tiempo presente y pasado, fundamentada en la memoria selectiva. En relación con el espacio, se manifiesta una lógica definitoria que sigue una estética determinada y funcional vinculada al lugar de ubicación. De esta manera, aquellas esculturas con mayor peso ideológico están situadas en el casco histórico y ensanches decimonónicos, las plazas y jardines para aquellas de menor carácter emblemático y en el extrarradio era inusual la instalación de monumentos (Reyero, 1999). Los monumentos escenifican «un hito en un lugar concreto que señala un significado/acontecimiento específico» (Krauss, 1979, p.63). Vinculado al espacio, el tiempo se estructura en función a la atribución de valores pasados al presente, a través de los cuales se justifica y legitima la nueva moralidad. Se configuran, así, los lugares de la memoria, como espacios colectivos donde disputar el poder. La idea central de este concepto acuñado por Pierre Nora en 1984, reside en proyectar una Historia sobre la que se construye la sociedad a partir de la selección de determinados recuerdos. Un lugar de la memoria es: 
Una entidad polirreferencial que puede desdoblarse en una multiplicidad de mitos culturales que son apropiados para diferentes propósitos ideológicos o políticos. Las esculturas conmemorativas, situadas en lugares de la memoria fueron utilizadas como un mecanismo para construir la historia de una nueva nación, facilitando la difusión de elementos culturales de conformación de la identidad mediante la apropiación de mitos culturales con fines políticos creando la historia identitaria de una nación (Navarrete, 2016, p.9).

Esta confluencia de las variables definitorias de los monumentos conmemorativos desencadena una inclusión de un conjunto de ideas o valores a ser resaltados para construir la identidad nacional y generando, a su vez, un silencio sobre aquello que es excluido. Diversos estudios han notificado la diferencia de género en la representación de las estatuas conmemorativas. Las esculturas que presentan figuras femeninas están infrarrepresentadas respecto a aquellas que representan a hombres ${ }^{1}$. Asimismo, las esculturas de carácter femenino están asociadas a estereotipos de género; ellas encarnan alegorías, sentimientos y en mayor grado el papel de madre bajo una mirada androcéntrica (Vega, 2016). El espacio público estructurado, como espacio político, privilegia y jerarquiza individuos. Aquellos excluidos de la esfera pública, como las mujeres, quedan relegados al espacio privado. En consecuencia, se reproduce una dicotomía hacer visible/ocultar creando un discurso normativo y válido sobre el que construir la Historia.

Ante esta problemática, es necesario repensar y resignificar los monumentos conmemorativos puesto que como artefactos selectivos del pasado, se articulan en la sociedad contemporánea produciendo significados y conformándose como elementos referenciales en el proceso de identificación. Este trabajo se focaliza en el marco interseccional, ante la finalidad de ampliar perspectivas y evitar una exposición de los resultados, únicamente, desde un enfoque unidimensional. Aquí es precisamente donde radica la relevancia de este trabajo; el objetivo no es únicamente identificar estereotipos de género sino, examinar el discurso identitario configurado a partir de las variables definitorias de las esculturas conmemorativas en dos capitales europeas para la identificación de similitudes y diferencias en la configuración de dicho discurso, para posteriormente, identificar su significado en la actualidad.

\section{Metodología}

La metodología empleada en este estudio responde a una combinación del método cuantitativo y cualitativo, sobre el cual se ha aplicado como estrategia fundamental un método comparativo, con el objeto de comprender las similitudes y diferencias para confrontar la configuración de la identidad nacional a través de la estatuaria conmemorativa. En primer lugar, se procede a la selección de dos capitales europeas, en este caso Madrid y Estocolmo, para su comparación, por ser dos ciudades en las cuales la cuestión de género forma parte de la agenda pública².

Una vez delimitada el área de estudio, se procede a la búsqueda de la ubicación de las estatuas figurativas mediante espacios webs oficiales de arte público, con el fin de crear un conjunto de datos (distrito, autor/a, año, información adicional). Finalmente, se seleccionaron un total de 212 en Estocolmo y 330 esculturas en Madrid. Seguidamente, se procedió a la visita in situ de las estatuas seleccionadas para la obtención de los siguientes datos descriptivos:

a) Género: masculino, femenino, neutro

b) Personaje 


\section{c) Características representativas}

d) Ubicación

Tras recabar la información, se efectuó un examen en el cual el género fue empleado como categoría de análisis; mediante la interpretación se relacionan elementos y estrategias diversas en una teoría unificadora permitiendo explicar cómo a partir del género las sociedades determinan los roles de identificación/acción.

\section{Resultados}

\section{1 ¿Cuántos y cuántas se representan?}

De las 212 esculturas figurativas que se analizaron en la ciudad de Estocolmo, únicamente el 32, $5 \%$ representa a mujeres frente al 50\% que representan a hombres. El 9,4\% de las esculturas presentan sexo sin determinar y en menor porcentaje, el $8 \%$, se representa conjuntamente figuras del género masculino y femenino. En Madrid, de las 330 esculturas que fueron examinadas, el $77,6 \%$ encarnan personajes del sexo masculino y sólo el $22,3 \%$ representan a mujeres. En este caso, las esculturas presentan un sexo determinado, fácilmente identificable, no como ocurre en Estocolmo donde se disponen esculturas sin atributos sexuales. Además, las esculturas que presentan ambos sexos conjuntamente son poco frecuentes.

Como se observa en la gráfica, el principal resultado muestra que las esculturas públicas, en ambas ciudades, se asocian al sexo masculino, situándose la representación de estatuas femeninas en valores por debajo de la mitad. Otro factor interesante que muestran los resultados es la notable diferencia entre ambos países. Mientras que Estocolmo presenta una diferencia menor entre la representación de ambos géneros. En cambio, en Madrid a pesar de ser mayor el número de estatuas figurativas analizadas, la desigualdad en relación a la representación de ambos géneros muestra valores más elevados respecto a Estocolmo.

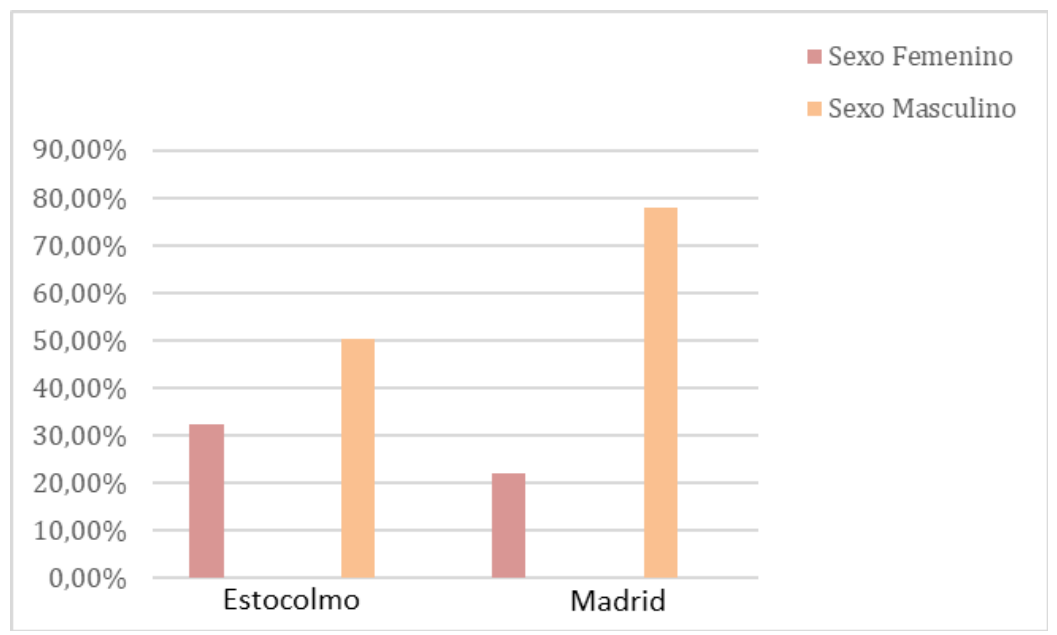

Gráfica 1. Representación según sexo de las figuras conmemorativas de Madrid y Estocolmo. Elaboración propia. 


\section{2 ¿Qué representan?}

En la ciudad de Estocolmo, del total de las estatuas que representan a mujeres el $46,3 \%$ se determinó que hacen referencia a alegorías y virtudes. Aquí se identificaron tres grupos. En primer lugar, aquellas esculturas que hacen referencia a condiciones adscritas a la feminidad. Se representan en mayor número la maternidad y la infancia e incluso hay dos estatuas dedicadas a la propia feminidad. Así como, el paso de niña a mujer, la juventud, la mujer como ama de casa y encarnando el rol de esposa. Pero, también condiciones abstractas consideradas negativas como el pecado o la vanidad. En segundo lugar, se determina una relación entre la figura femenina y la naturaleza. Se observa la adjudicación de fenómenos meteorológicos a las esculturas de mujeres como la niebla, la mañana o el mar. Finalmente, la representación de valores patrióticos como la Nación, la cual es representada como una figura femenina en diversas ocasiones. Hay que destacar el hallazgo de una escultura femenina dedicada a la minifalda. El 24,6\% se refieren a esculturas femeninas de carácter anónimo. Son aquellas figuras con una función ornamental que suelen aparecer asociadas a fuentes y situadas en espacios ajardinados. Hay que resaltar que la mayoría reciben nombres de mujer como Sophie, Camille, Jeannette, Mimi, Bianca o Lena. El 14,4\% se asocian con personajes mitológicos, los cuales se diferenciaron en dos grupos. Por un lado, aquellas figuras que representan a diosas de la mitología clásica como Atenea, Diana, Venus, Dafne y las Ninfas. Por otro, esculturas que representan a diosas de la mitología nórdica, Sigyn, los Dioses del mar Ägir y Ran y sus nueve hijas. Se observa cómo las diosas de la mitología griega se representan con mayor frecuencia que las figuras de la mitología romana y nórdica. Únicamente el 11,5\% representa a personajes ilustres. Estas esculturas simbolizan a actrices como Greta Garbo y Margaretha Krook. La escritora Fredrika Bremer, la educadora Elsa Berg y la pintora y feminista Siri Derkert. Destaca la representación de activistas y políticas que lucharon por los derechos de las mujeres como Ellen Key, Anna Sterky, Anna Lindhagen. Hay que señalar que todas ellas son de nacionalidad sueca, excepto Anna Sterky quien nació en Dinamarca pero desarrolló su trabajo como política en Suecia. El 2,9\% corresponde a personalidades relacionadas con la realeza. Únicamente se representa a Märtha av Sverige, princesa de Suecia y Kristina Gyllenstierna, noble que dirigió la resistencia contra Dinamarca.

Al analizar los datos en comparación con las esculturas referentes al sexo masculino, se expuso que el $42 \%$, encarnan personajes ilustres de nacionalidad sueca (a excepción de Willy Brandt, político alemán y premio nobel de la paz quien se refugió en Suecia tras su huida de las fuerzas nazis). Entre ellos, de mayor a menor grado de representación se disponen: políticos (6 representaciones), escritores (5), científicos (4), sacerdotes (3), deportistas (3), con dos representaciones educadores, pintores, compositores, escultores, y finalmente, con una representación, un inventor, veterinario, meteorólogo, arquitecto, empresario, humorista, cantante de ópera, poeta y un oficial del ejército. El 16,8\% alude a esculturas masculinas de carácter anónimo. Estos suelen representar a niños o jóvenes, cuya función es decorativa. A diferencia de las esculturas femeninas estas no tienen nombres personales. El 14\% representan virtudes relacionadas con el sexo masculino como la fuerza, la humanidad, la vejez y la vida o la imaginación; así mismo se homenajea a través de la representación de la figura masculina a víctimas de la guerra, el primer velero o la navegación, a la figura del trabajador en general y de los cultivos de centeno y portuarios en particular. En relación a los trabajadores, hay que destacar cómo hay una escultura que representa a las vacaciones. El 11,2\% se refiere a héroes y personajes mitológicos. Entre ellos destacan héroes como San Jorge y el dragón, de la mitología nórdica, Sjöguden, dios del mar y Thor. En su mayoría encarnan a personajes de la mitología 
clásica como Orfeo, Tritón, Apolo, Centauro, Ícaro y Dionisio. El 10,2\% son esculturas que representan a los reyes de Suecia. Entre ellos Biger Jarl (conde y regente de Suecia), Gustav III, Gustav Vasa, Karl XII, Karl XIII Gustav V o Gustav VI. Finalmente, el 5,6\% son estatuas que aluden al deporte: los juegos olímpicos, lanzamiento de peso, jabalina, relevo y boxeo.

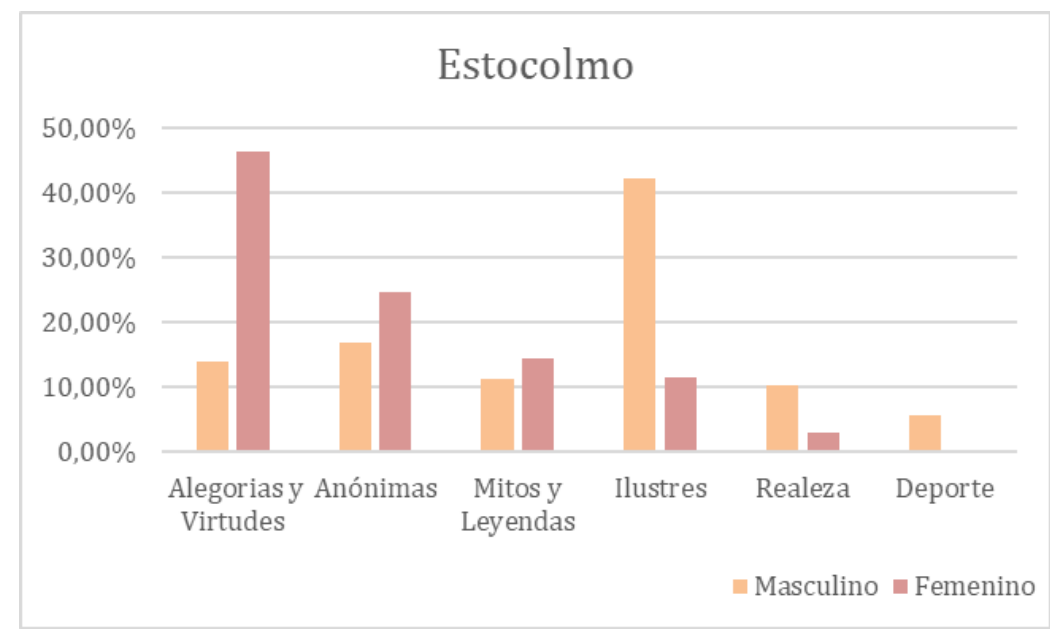

Gráfica 2. Figuras representadas en las esculturas conmemorativas de Estocolmo. Elaboración propia.

En Madrid, las estatuas femeninas representan en un $30 \%$ al conjunto de personajes de la mitología clásica, a santas y Vírgenes. De la mitología romana se representa a Venus, en cambio de la griega a Rea, Talía, Terpsícore, Diana, Era, Andrómaca y el rapto de Europa. A santas como Santa María de la Cabeza, Santa Bárbara y Santa Rosa de Lima. Asimismo, las vírgenes constituyen el mayor grupo de representación, entre ellas: la Virgen María, la Virgen de los Desamparados, de la Misericordia o la Virgen Blanca y de la Almudena. También, un 30\% de las estatuas se refieren a alegorías y virtudes. La maternidad y la fertilidad son estatuas que representan condiciones adscritas a la feminidad. El dolor, la fortaleza y la constancia como virtudes femeninas. Asimismo, como ocurre en Estocolmo se representa, no la Nación sino, en este caso, a la Patria en un cuerpo femenino. En este caso, destaca cómo se atribuyen cualidades como la fama, la historia, la victoria, la arquitectura y la paz. El 13,7\% hace referencia a mujeres relacionadas con la realeza. Aquí se representan a las reinas Isabel la Católica, Isabel II, Berenguela de Castilla, Bárbara de Braganza, Sancha I de León, María Cristina de Borbón, Doña Urraca y la Duquesa de Osuna. También, con un 13,7\% se representan a personajes anónimos o característicos de la ciudad. Entre ellos destaca la Violetera, la abuela rockera, mujer con cántaro, mujer con espejo, la mensajera o joven bailando. Finalmente, sólo el 12,3\% representa a personajes femeninos ilustres. Clara Campoamor, Emilia Pardo Bazán, la escritora Beatriz Galindo y la actriz Loreto Prado, todas de nacionalidad española excepto la primera dama de Argentina, Eva Perón.

De las esculturas que se refieren a personajes masculinos el 63,4\% representan a personajes ilustres de nacionalidad española excepto 27 de ellos. Los más representados son: escritores, militares y políticos, con 32, 20 y 17 representaciones respectivamente. Seguidos de doctores y pintores, así como músicos e intelectuales. Con menor representación: marqueses, 
conquistadores, botánicos, inventores, toreros abogados, ingenieros científicos y religiosos. Finalmente, con una representación se disponen un pedagogo, historiador, futbolista y jardinero. El 19,8\% corresponde a reyes de España como Felipe IV, Felipe III, Felipe II, Carlos, Alfonso, Fernando o el rey Juan Carlos I; así como Iñigo Arista, Ramón Berenguer IV o los Reyes Godos. El 11,2\% a santos como San Pedro, San Gerardo, San Pablo, el Sagrado Corazón de Jesús, San José y San Isidro. Además de héroes mitológicos como Apolo, Neptuno, Hércules, Orfeo, Baco, Saturno, Fauno y el dios Atlas. Únicamente el 3,8\% de esculturas masculinas son anónimas. Estas hacen referencia a profesiones como el vendedor de cupones, el farolero, el pintor y el barrendero. Además de personajes que presentan acciones como el lector y el observador.

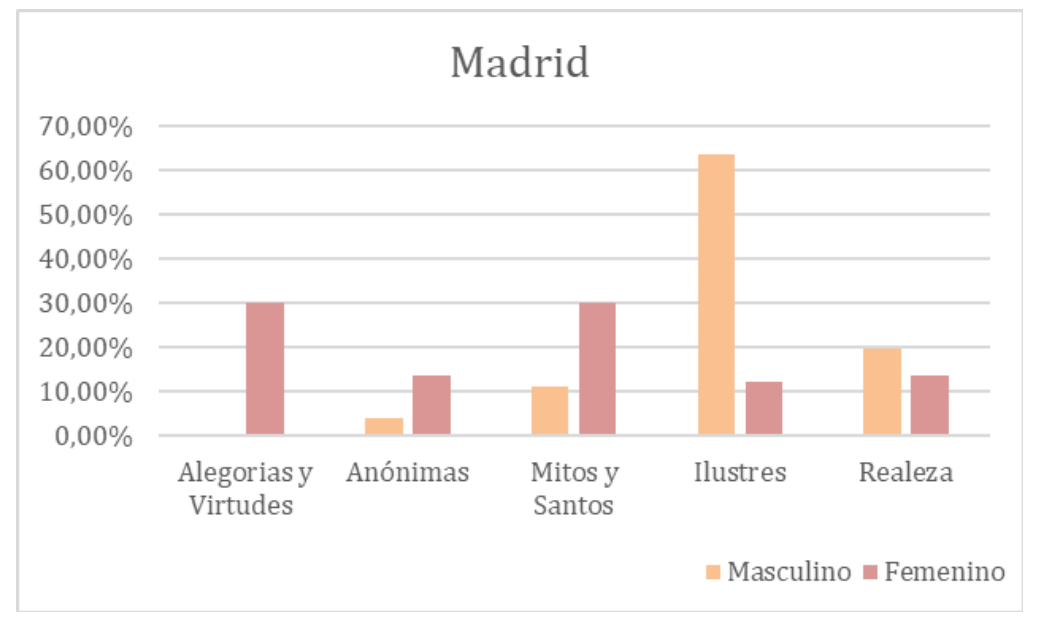

Gráfica 3. Figuras representadas en las esculturas conmemorativas de Madrid. Elaboración propia.

Al ejecutar una comparación entre ambas ciudades se determinó que en Madrid se sitúa en primer lugar el grupo relacionado con la mitología y religión, por la cantidad de representaciones de vírgenes y santas, hecho que no ocurre en Estocolmo. En ambas ciudades se observó la representación de Venus como única diosa de la mitología romana, relacionada con el amor y la belleza. Respecto al grupo de virtudes y alegorías se determinó que la maternidad es un concepto que se representa en ambas ciudades así como, la representación de la Patria/ Nación. Como diferencias se observó la relación naturaleza-mujer propia de Estocolmo y la relación entre mujer-virtudes de Madrid. En esta última ciudad, destaca cómo se adscriben a la condición femenina el dolor o la constancia. Sobre las reinas destaca cómo en España se representan mucho más que en Suecia donde únicamente se hace alusión a una princesa, a pesar de haber tenido reinas y no consortes. Respecto a la diferencia que se observó sobre los personajes anónimos en Madrid, estos no están relacionados con las fuentes y no tienen nombres propios sino que responden a personajes característicos de la ciudad. Finalmente, los personajes ilustres femeninos son en menor medida representados en Madrid; comparten figuras clave del movimiento feminista de cada país, así como una escritora y una actriz. 
En Estocolmo, en el caso de las figuras femeninas representadas de cuerpo entero el $24.1 \%$ se representan desnudas. Son representaciones de mujeres jóvenes, esbeltas, bellas y con los cabellos largos. Presentan una actitud pasiva y ensimismada o ausente. Aparecen de pie, sentadas, recostadas o arrodilladas. Están situadas en el suelo o pedestales muy bajos. Son mujeres anónimas que encarnan la niebla, la mañana, el mar, la maternidad, feminidad o la infancia; así como la diosa del bosque y la caza Diana y Sigyn, la fiel esposa del dios Loki. El $16,5 \%$ se presentan vestidas con vestidos largos que cubren sus piernas, excepto las niñas que se representan con vestidos o pantalones cortos. Estas mujeres se representan no muy delgadas, son mayores y el pelo lo llevan recogido. Entre ellas se disponen las representaciones de personajes ilustres, miembros de la realeza, la maternidad y el ama de casa. Asimismo se distingue un grupo de guerreras quienes, presentan una actitud activa y desafiante como Kristina Gyllenstierna y Nación (Moder Sevea). El 5,8\% muestran relieves o son figuras con forma corpórea abstracta. Entre ellos destacan los relieves de Anna Sterky, Anna Lindhagen y La fuente de la vida. El 2,9\% son bustos como el de Athenea. En el caso de los hombres, no es tan notable la diferencia. El 31,1\% representa tanto figuras masculinas desnudas como vestidas. Únicamente, 20 esculturas masculinas se representan desnudas con atributos sexuales y 10 semidesnudos. Todos son fuertes, jóvenes y presentan una actitud activa. Se identifican con personajes mitológicos, y el deporte, así como una proliferación de niños. Destaca la figura de August Strindberg, el único personaje ilustre plasmado desnudo. El 26,4\% son bustos sobre pedestal elevado, entre los que se representa sobretodo personajes ilustres. El $9,4 \%$ no se identifica si van vestidos y el $1,8 \%$ son relieves.

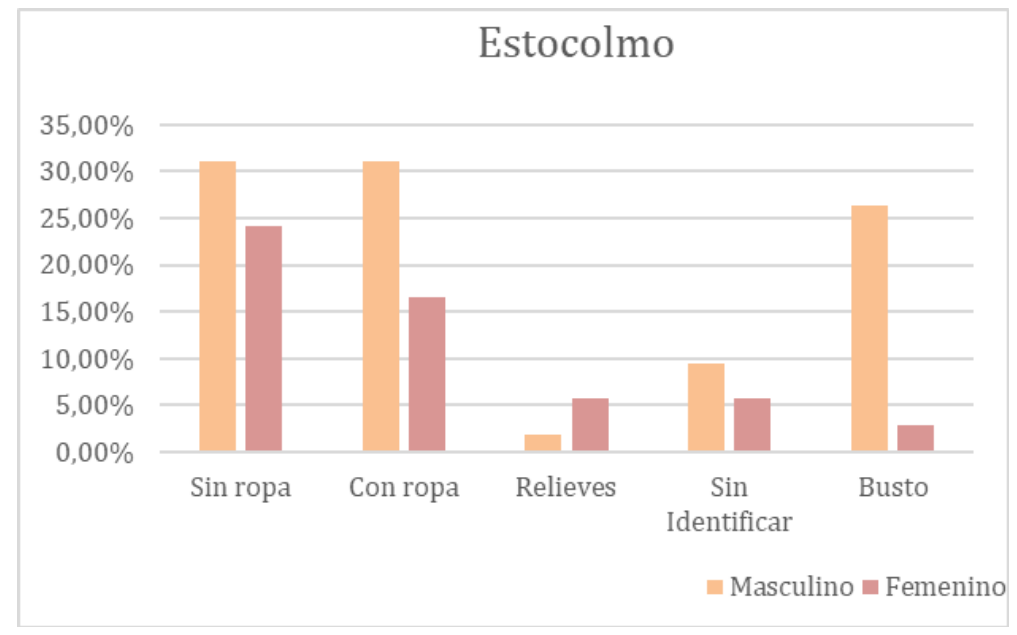

Gráfica 4. Características de las figuras representadas en las esculturas conmemorativas de Estocolmo. Elaboración propia

En Madrid, la mayoría de mujeres se representan vestidas, en concreto el $61,6 \%$. Sólo el $26 \%$ se representan desnudas pero, en su mayoría, sólo muestran un pecho. Estas hacen referencia a personajes mitológicos como Venus, Terpsícore, Diana, El rapto de Europa, Andrómaca y la 
Victoria Alada; mujer sedante y maternidad. El 10,9\% son bustos, en referencia a personajes ilustres como la Duquesa de Osuna, Clara Campoamor, Eva Perón o Ernestina Manuel de Villena. Finalmente, el $1,3 \%$ son figuras abstractas. Las esculturas masculinas se presentan vestidas, en un $61,8 \%$. El $28,7 \%$ son bustos. El $7 \%$ se representan desnudos en relación a personajes mitológicos. El $1,5 \%$ son relieves y el $0,78 \%$ son representaciones abstractas.

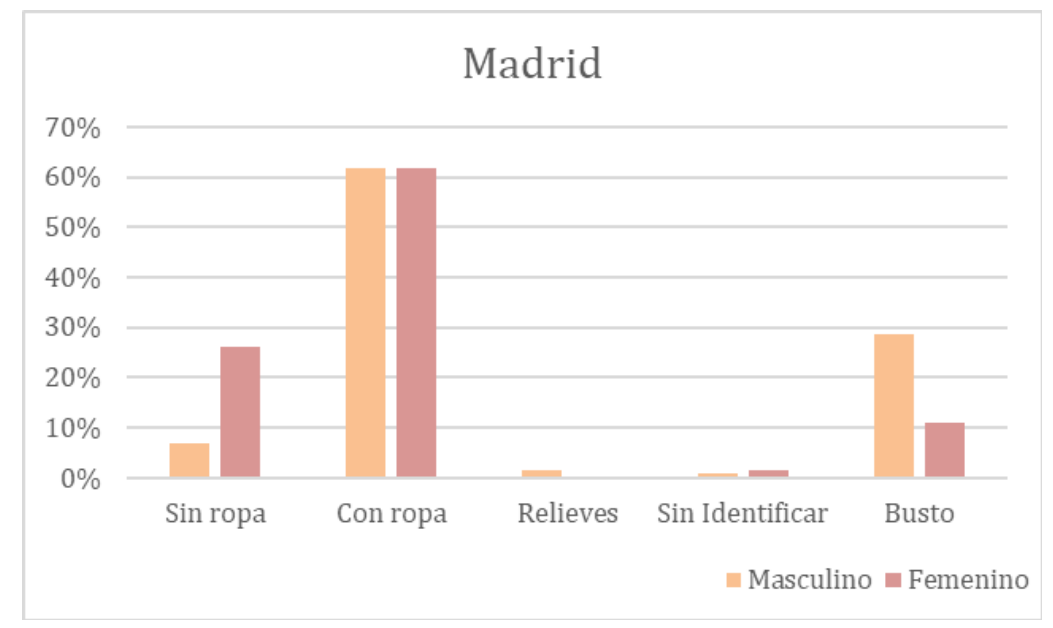

Gráfica 5. Características de las figuras representadas en las esculturas conmemorativas de Madrid. Elaboración propia.

Como se observó, aquellas mujeres que se representan desnudas reproducen estereotipos femeninos asociados a la belleza. Estas, son mujeres anónimas que responden a una función ornamental o bien representan a personajes mitológicos. Aquellas que aparecen vestidas son personajes ilustres, respetables que encarnan la moralidad. Los hombres representados sin ropa también responden a estereotipos de género, son fuertes, musculosos y presentan una actitud beligerante. La diferencia más notable entre ambas ciudades responde a la abundancia de representación de la desnudez en Estocolmo frente a la escasez de Madrid, donde la mayoría de personajes aparecen vestidos.

\section{4 ¿Dónde se representan?}

En el análisis de las estatuas en relación al lugar, se efectuó una segmentación de la ciudad por barrios: el centro histórico, el centro moderno y administrativo, el barrio bohemio, el barrio acomodado y el residencial. En todos los barrios, generalmente, predominan las figuras masculinas frente a las femeninas. En cuanto a las figuras masculinas en el centro histórico, se representan a Reyes y en el resto de barrios personajes ilustres. Destaca cómo en los barrios residenciales predominan además, personajes anónimos cuya finalidad es ornamental. Respecto a las esculturas de carácter femenino en Estocolmo prevalecen las alegorías y virtudes, junto con las anónimas en los barrios residenciales. En Madrid destacan personajes ilustres o característicos del barrio y en alguno de ellos vírgenes y santas. Por tanto, ambas ciudades presentan una disposición de las esculturas bastante similar. 


\section{Discusión de los resultados}

La identidad es un término complejo en su definición y comprensión. Tomando como referencia a Navarrete, la identidad se refiere a un concepto necesario pero a la vez imposible de una representación precisa y definitiva (Navarrete, 2013). Necesario debido a que significa al sujeto pero, a su vez, es una noción intangible que carece de percepción absoluta. Ante la incapacidad intrínseca de dicho concepto de representación única y universal, la identidad es formulada en función del paradigma de investigación que se adopte. El proceso de identificación permite determinar y discernir la configuración de la identidad en un momento histórico-temporal específico y concreto, en tanto que el sujeto es atravesado por diferentes elementos. En virtud de lo cual, la identidad se constituye en el acto de lo cambiante y dialéctico.

Cuando se habla de la identidad de un sujeto individual o colectivo hacemos referencia a procesos que nos permiten asumir que ese sujeto, en determinado momento y contexto, es y tiene conciencia de ser él mismo, y que esa conciencia de sí se expresa (con mayor o menor elaboración) en su capacidad para diferenciarse de otros, identificarse con determinadas categorías, desarrollar sentimientos de pertenencia, mirarse reflexivamente y establecer narrativamente su continuidad a través de transformaciones y cambios (De la Torre, 2001, p.82).

Desde el ámbito discursivo, la identificación es comprendida a modo de una sucesión en continua construcción, la cual no es concluyente.

la identificación se construye sobre la base del reconocimiento de algún origen común o unas características compartidas con otra persona o grupo o con un ideal, y con el vallado natural de la solidaridad y la lealtad establecidas sobre este fundamento [...] En contraste con el «naturalismo» de esta definición, el enfoque discursivo ve la identificación como una construcción, un proceso nunca terminado: siempre «en proceso» [...] Y puesto que como proceso actúa a través de la diferencia, entraña un trabajo discursivo, la marcación y ratificación de límites simbólicos, la producción de «efectos de frontera». Necesita lo que queda afuera, su exterior constitutivo, para consolidar el proceso (Hall y Du Gay, 1996, pp.15-16).

Desde la esfera psicoanalítica, la identificación responde a un proceso de asimilación de la otredad para la transformación del yo. Conforme la propuesta de Lacan, en la Concepción del Estadio del Espejo, la identificación principal se produce cuando el sujeto reconoce y asume su imagen reflejada en el exterior, por vez primera, la cual desencadena diversas identificaciones formadoras del yo. No obstante, esa identificación originaria es fundamentada a partir del reflejo del yo ideal.

Esta forma sitúa la instancia del yo, aun desde antes de su determinación social, en una línea de ficción, irreductible para siempre por el individuo solo [...] La toma total del cuerpo, gracias a la cual el sujeto se adelanta en un espejismo a la maduración de su poder, no le es dada sino como Gestalt, es decir en una exterioridad donde sin duda esa forma es más constituyente que constituida (Lacan, 1966, pp.87-88).

El ser humano construye su realidad a partir de un proceso identificativo cimentado en la articulación de semejanzas y diferencias. Siguiendo a Hegel en su Teoría del Reconocimiento 
(1807), la autoconciencia es reconocimiento y para que este se dé, se produce una hostilidad entre dos autoconciencias que entran en relación: la del sujeto, que es la conciencia independiente, el yo igual al yo y la negadora que es la dependiente esencial para la otra autoconciencia. Entre las dos se da una lucha por el reconocimiento, de ahí que no haya una independencia absoluta de las conciencias, la autoconciencia es intersubjetiva, encuentra su verdad en relación con la otra autoconciencia. Tal y como manifiesta Beauvoir «La alteridad es una categoría fundamental del pensamiento humano» (1949: 51). Ningún colectivo se define como Uno sin enunciar inmediatamente al Otro frente a sí.

En esa reafirmación manifestada en la oposición, del yo, frente al otro se configura la identidad cultural, ante la necesidad de pertenencia a un grupo con el que compartir, conformando un nosotros frente a un vosotros.

La identidad cultural de un pueblo viene definida históricamente a través de múltiples aspectos en los que se plasma su cultura, como la lengua, instrumento de comunicación entre los miembros de una comunidad, las relaciones sociales, ritos y ceremonias propias, o los comportamientos colectivos, esto es, los sistemas de valores y creencias [...] Un rasgo propio de estos elementos de identidad cultural es su carácter inmaterial y anónimo, pues son producto de la colectividad (González, 1999, p.43).

La colectividad, la constitución de un nosotros, será la clave para legitimar los sistemas de poder. La identidad cultural se configura como una estructura simbólica imprescindible para la identificación de una comunidad frente a otras. A la vez que reafirma la propia comunidad, mediante la representación de elementos constituyentes y compartidos (lenguaje, arte, tradiciones, etc.) que permiten a un sujeto identificarse, se posiciona en subordinación a la identidad nacional, sentimiento de pertenencia a esa colectividad sobre el cual se estructuran los elementos simbólicos. La nación es configurada como un todo homogéneo, adoptando características de individuo que permiten la autoafirmación mediante un discurso sometido al interés propio, en negación y contraposición frente a las otras naciones/individuos. Se crea una visión unilateral en oposición a los otros, generando un pensamiento binario. La nación, tal y como establece Calhoun en Nationalism (1997), hace referencia a una colectividad compuesta de sujetos equivalentes y a su vez, un sujeto colectivo con atributos humanos. La sociedad dentro de la nación es definida como una masa homogénea, obviando cualquier atisbo de diferencia. Los símbolos permiten al individuo significar su identidad nacional, entre los cuales la bandera y el himno configuran un sentimiento patriótico que ahonda en el individuo a través de la emoción. La exaltación y glorificación de los símbolos y representaciones constituirá la estrategia principal en la legitimación del poder. Como afirma Fernando Savater en Contra las Patrias (1984), cómo seres humanos necesitamos sentirnos que formamos parte de algo y por ello cualquier cosa que exalta y tonifica al hombre nos parece inmediatamente conmovedora. La más prioritariamente humana de nuestras aspiraciones es la de sabernos pertenecientes a una unidad superior, a la vez dotada y dadora de significado (Savater, 1984).

En este contexto, es donde los monumentos conmemorativos, como símbolos representacionales de los valores del Estado, configuran nuestra identidad. El discurso se fundamenta en el dualismo sexual, donde la categoría de mujer, a quien se relega al espacio privado e íntimo, se configura en oposición a la de hombre, a quien pertenece el espacio público y político, como se identifica en el mayor número de esculturas masculinas dispuestas en las calles. Este hecho impone una narración esencialista, asegurando la identificación de la población con uno de 
los dos sexos: hombre o mujer y negando cualquier discurso fuera de la heteronormatividad. ¿Cómo son estos hombres y mujeres? Las representaciones de carácter femenino se estructuran en dos esferas antagónicas: las mujeres adscritas a la categoría de belleza (anónimas, pasivas y condición ornamental), las cuales son más abundantes, frente a la categoría de inteligencia (nombre propio, activas, respetadas), quienes constituyen una excepción. Las representaciones masculinas no se estructuran en una diferenciación corpórea, todas hacen referencia a su capacidad intelectual asociada al trabajo. Todos ellos y ellas presentan rasgos caucásicos. En el caso de Madrid destaca la representación de valores religiosos y patrióticos a través de la santería y militares, por ello es difícil observar cuerpos desnudos.

Precisamente porque las identidades se construyen dentro del discurso y no fuera de él, debemos considerarlas producidas en ámbitos históricos e institucionales específicos en el interior de formaciones y prácticas discursivas específicas, mediante estrategias enunciativas específicas. Por otra parte, emergen en el juego de modalidades específicas de poder y, por ello, son más un producto de la marcación de la diferencia y la exclusión que signo de una unidad idéntica y naturalmente constituida: una «identidad» en su significado tradicional (es decir, una mismidad omniabarcativa, inconsútil y sin diferenciación interna) (Hall y Du Gay, 1996, p.18).

Pero aquí se vislumbra un problema, la exclusión de las diferencias de todo aquello que no esté situado en el marco normativo establecido por el Estado-Nación. La cuestión reside en una narración del pasado negadora de la diferencia social, que configura una invisibilización, una no-existencia en la cual resulta imposible constituir una imagen reflejada que pueda constituir el yo. En la configuración de la identidad individual intervienen diferentes categorías de orden social como el género, la clase social, etnia, sexualidad, dis/capacidad. El patrimonio cultural en general y los monumentos conmemorativos en particular (por su disposición en el espacio público y su carácter figurativo) debido a su carácter simbólico poseen capacidades para la configuración de identidades. Por ello:

Es crucial comprender cómo las imágenes y las historias del pasado se construyen en el sector del patrimonio y cómo se seleccionan los artefactos para formar parte de nuestro patrimonio cultural [...] Tienen el potencial de afectar nuestra comprensión de quién pertenece al presente y al futuro [...] a menudo dando forma a imágenes y narrativas en torno a aquellas personas que se consideran oficialmente honorables, memorables y deseables en una sociedad. Por ello, es incluso más importante reflexionar y problematizar las identidades que una sociedad quiere para preservar y recordar (Grahn, 2018, p.256).

En este marco, incorporar un enfoque interseccional permite percibir los diferentes modos a través de los cuales las categorías sociales (género, etnia, sexualidad, clase social, edad, etc.) conforman las estructuras de poder y su consecuente desigualdad en los espacios sociales que infieren en el modelado de las identidades individuales. En las sociedades actuales, plurales, diversas y multiculturales es necesario reflexionar acerca del significado que tienen en ellas los monumentos conmemorativos. El espacio urbano se identifica actualmente con los no-lugares, es decir espacios públicos homogéneos, estandarizados, deshumanizados que hacen referencia a lugares destinados al consumo de masas (Gómez, 2004) en los cuales los monumentos públicos y el concepto identitario se desvanecen. Sin embargo, esta aparente invisibilidad, por su constante exposición y la carencia de vínculo entre sociedad y espacio, deviene en una naturalización de ideas jerarquizadas que configuran un imaginario colectivo en el cual, se 
establecen las relaciones de poder. Para desestructurarlas son necesarias las representaciones de valores e ideas integradas en sociedades plenas, justas e inclusivas que permitan alcanzar el desarrollo integral de los individuos, liberando el espacio público de elementos políticos legitimadores de las desigualdades.

\section{CONCLUSIONES}

Los monumentos conmemorativos responden a una finalidad política, ya que mediante la representación simbólica de valores y de ideas rescatadas del pasado, conforman una narración didáctica subordinada a la autoridad del Estado-Nación. El objetivo es configurar una masa homogénea y heteronormativa donde no haya lugar a las diferencias, como medio de asentar y legitimar el poder. En el análisis de las esculturas conmemorativas de Madrid y Estocolmo se determina que el discurso identitario se enmarca en la diferencia sexual y los estereotipos asociados a cada género siendo, en el caso de Madrid de un marcado carácter religioso y militar.

Ahora bien, cabría reflexionar cómo se significan estas esculturas conmemorativas en los marcos económicos y sociopolíticos actuales. A priori el carácter urbanístico e ideológico, así como los ritmos de vida conducen a una percepción casi invisible de dichas esculturas. Sin embargo, su continua presencia se traduce en una naturalización de las ideas que están configurando la identidad de los individuos. Aquí es donde radica realmente el problema ya que, en el proceso de identificación a partir del cual se va constituyendo nuestra identidad, la función de estas imágenes es determinante. En primer lugar, porque son transmisoras y legitimadoras de la desigualdad y la diferencia. Hecho incompatible con el eje político de los sistemas democráticos justificado en el principio de igualdad. Tal y como se manifiesta en las Constituciones, junto con legislación específica, se determina la prevención de conductas discriminatorias y ejecución de políticas públicas para hacer efectivo el principio de igualdad. En segundo lugar, las esculturas conmemorativas no representan las sociedades actuales definidas en la multiculturalidad, ya que estos monumentos presentan valores rescatados del pasado, determinantes para la construcción de una sociedad antigua. Por tanto, ¿qué sentido tienen las esculturas conmemorativas en el espacio urbano actual, desde la perspectiva en las que originalmente se fundamentaron? En cuya respuesta, podríamos remitirnos a la capacidad que posee el patrimonio cultural (en cuanto a la selección para su conservación y su disposición en determinados espacios) para la configuración de la identidad; pues en su dominio reside la posibilidad de crear una sociedad más inclusiva y diversa.

\section{REFERENCIAS}

Beauvoir, S. (1949). El segundo sexo. Buenos Aires: Siglo XX. 1965.

Calhoun, C. (1997). Nationalism. Buckingham: Open University Press.

De la Torre, C. (2001). Las identidades, una mirada desde la psicología. La Habana: Centro de Investigación y Desarrollo de la cultura cubana Juan Marinello. 
Gamboa, P. (2003). El sentido urbano del espacio público. Bitacora, 7(1), 13-18.

Gómez, F. (2004). Arte, ciudadanía y espacio público. On the W@terfront, 5, 36-51.

González, I. (1999). Conservación de bienes culturales: teoría, historia, principios y normas. Madrid: Ediciones Cátedra.

Grahn, W. (2018). The politics of heritage: how to achieve change. En R. Wilson y W. Grahn, (Eds.). Gender and Heritage: Performance, Place and Politics (pp. 255-268). London and New York: Routledge.

Hall, S. y Du Gay, P. (1996). Cuestiones de identidad cultural. España: Amorrortu editores.

Krauss, R. (1979). La escultura en el campo expandido. En H. Foster (Ed.). La posmodernidad (pp. 59-74). Madrid: Kairós.

Lacan, J. (1966). Escritos. Ciudad de México: Siglo veintiuno editores.

Malo, C. (2006). Arte y Cultura Popular. Ecuador: Centro Interamericano de Artesanías y Artes Populares, CIDAP, Universidad del Azuay.

Navarrete, Z. (2013). Formación e identidad. En P. Ducoing (coord.) Procesos de formación 2002-2011 (pp. 309-364). Ciudad de México: ANUIES/COMIE.

Navarrete, D. (2016). Los monumentos públicos en Tegucigalpa. Revista Arte \& Cultura, 2, 8-19.

Reyero, C. (1999). La escultura conmemorativa en España. La edad de oro del monumento público, 1820-1914. Madrid: Cátedra.

Reyero, C. (2003). Monumentalizar la capital. La escultura conmemorativa en Madrid durante el siglo XIX. En C. Lacarra, y C. Giménez (Coords.) Historia y política a través de la escultura pública 1820-1920 (pp. 41-62). España: Colección Actas.

Savater, F. (1984). Contra las patrias. Barcelona: Tusquets.

Solá, M. (1973). De la ordenación a la coordinación. CAU: construcción, arquitectura, urbanismo, 27,106-114. 
Vega, E. (2016). ¿Una violencia invisible? Las mujeres en los monumentos públicos. Boletín de Arte, 37, 213-225.

Zárate, V. (2003). El papel de la escultura conmemorativa en el proceso de construcción nacional y su reflejo en la ciudad de México. Historia Mexicana, 53(2) ,417-446.

\section{NOTAS}

1. En este sentido, se han realizado campañas de denuncia respecto al poco número de estatuas públicas que representan a mujeres. Véase como ejemplo en Reino Unido el proyecto inVISIBLE man, o en Estados Unidos el colectivo Where Are The Women?

2. Tanto Suecia como España, contemplan una legislación enfocada a la promoción de la igualdad de género. Asimismo, son países referentes en incluir legislación referente a la erradicación de la violencia de género. 